\section{Camus y el}

existencialismo

Francisco

Gutiérrez Sánchez*

\section{RESUMEN}

El propósito de este artículo es analizar el pensamiento filosófico de Albert Camus en relación con el movimiento existencialista de la época, y examinar desde el panorama existencial la vinculación del filósofo del absurdo a esta corriente filosófica. Se analizarán aspectos fundamentales de la filosofía existencial en general para determinar si Camus es o no existencialista. Para ello haremos un recorrido de los temas principales de la filosofía camusiana como por ejemplo el absurdo, la nostalgia humana, la existencia, la rebelión, etc.

\section{INTRODUCCIÓN}

La vigencia del pensamiento filosófico existencial de Albert Camus en el comienzo del siglo XXI es verdaderamente impresionante; dentro de un marco político, social, económico, moral, religioso, saturado por ambigüedades e interpretaciones subjetivas de libros y textos sagra-

* Licenciado en Filosofía. Actualmente es encargado de la Cátedra de Filosofía de la Educación de la Universidad Estatal a Distancia y profesor de Ética en la Universidad de Costa Rica. dos, visiones del mundo impositivas por parte de los máximos poderes mundiales, cobra suma importancia retomar el análisis del pensamiento camusiano.

Los tratados de paz (a los que tanto les dio importancia Camus) los tratados y convenios económicostecnológicos, la temática sobre los valores humanos, ya sean personales o sociales, los efectos de la denominada globalización, la educación y la cultura del ciudadano del futuro, sus medios y fines, la moral y la política como instrumentos de poder social sobre los pueblos son algunos de los temas actuales controversiales y que de una manera o de otra son discutidos y analizados por Camus a lo largo de toda su obra.

Un pensamiento que se dedique o se consagre a defender al ser humano en su existencia plena, y a valorar la vida como un valor supremo digno de respeto, es un pensamiento actual $y$, más que eso, es una filosofía vivencial concreta para nada abstracta.

\section{La existencia en Camus}

Una de las ideas fundamentales de la filosofía existencial es que el hombre-ante todo- es existencia y 
que ésta se da en la determinación y en la realización del ser como proyecto existencial.

Camus, identificado en algunas partes con esta manera de pensar, no concibe un paraíso divino después de la muerte como justificación al dolor y a la miseria en esta tierra. No es posible un Dios que acepte y permita la destrucción y el dolor humano. El hombre está sólo en este mundo y construye su existencia con base en su libertad.

En cuanto a si Camus es o no existencialista lo iremos analizando poco a poco, retomando mucho de lo que nos legó en sus obras y, por supuesto, analizando sus ideas filosóficas en relación con el movimiento existencialista, que tuvo su mayor auge al acercarse la mitad del presente siglo, son muchas las partes de su temática en las que plasma su pensamiento, una obra bastante extensa y variada, rica en mensajes, conflictos, angustias; sin faltar esa lucidez y honestidad que lo caracterizó.

En medio de una serie de convulsiones sociales y políticas empieza a desarrollar su intelecto y su interés por la filosofía (aunque al igual que otros pensadores, no le gustaba que lo llamaran filósofo). Uno de sus rasgos más característicos era su pasión por el periodismo crítico, dentro del cual mantiene con firmeza una posición honesta y profunda en pro de la vida humana.

Algunos consideran a Camus como un hombre trágico, quizá por las obras escritas en sus primeros años de literato, una etapa difícil en que tuvo que definirse políticamente ante un momento en que la angustia hacia su aparición y la convulsión social se desbordaba en las calles. Una etapa en donde tiene que aceptar situaciones escabrosas y existir con ese pesado fardo que a veces se torna la existencia, cuando el absurdo y la desesperación asoman sus filosas garras.

Para poder definir a Camus es necesario conocer toda su obra y el momento histórico en el cual se desenvolvió. A veces podemos pensar en descripciones acomodaticias acerca de su personalidad y su obra literaria, tal vez, por no profundizar en su evolución filosófica.

Albert Camus, nació en Argelia colonia francesa, el 7 de noviembre de 1913. Su padre era de origen francés y su madre era de ascendencia española.

Sufre a muy temprana edad la muerte de su padre, quedando al cuidado de su madre, la cual no 
sabia leer ni escribir; trabajaba como mujer de limpieza para ganar el sustento de la familia. Podría decirse que esta situación económica pudo ser un obstáculo para la formación de Camus, pero la gratituidad de la escuela francesa le permitió desarrollar sus capacidades.

Camus se distinguió desde temprana edad. En la adolescencia leía algunos de los grandes autores, entre ellos a Malraux y Dostoievski, los cuales influirán en su obra posterior.

Siente gran afición por el fútbol y la natación, siendo esta última algo sagrado para él, hecho que podemos corraborar al leer sus obras y al ver la importancia que da a esos momentos de placer en el agua en toda su obra: el sol, el mar, las playas y la naturaleza en sí ocuparán un lugar preponderante. La naturaleza es como una madre que cobija y da alivio en los momentos difíciles y sirve de refrescante aliento, que revitaliza las energías para poder enfrentar la vida con mayor fuerza.Tal es el caso de su obra: La mujer adúltera, que se entrega a la noche en toda su plenitud.

Sus estudios secundarios los realiza en el Liceo de Argel. A los diecisiete años sufre de tuberculosis, lo cual hace que tenga que abandonar su hogar e ingresa luego en la Universidad de Argel. En ella empieza a inclinarse por el mundo de la Filosofía.

En cuanto a política se refiere, ésta ocupará gran parte de su juventud y madurez. Empieza con su adhesión a un movimiento antifascista, participa en varias manifestaciones y se dará a conocer como un antiimperialista de tinte socialista.

Poco después contrae matrimonio pero éste dura muy poco. Este hecho repercutirá más adelante en su obra, pues son muy comunes las historias de amor en su obra que no concluyen de modo romántico: Meursault y María en El extranjero, por ejemplo.

En 1934 ingresa al partido comunista de Argel y se le responsabiliza de la propaganda política (en ese país). En 1945 se retira de dicho partido aduciendo que el comunismo se interesaba muy poco por el colonialismo, silenciaba sus injusticias y poco había hecho por los argelinos que estaban sufriendo grandes calamidades. También en El hombre rebelde nos hablará con gran profundidad de los desacuerdos que fueron surgiendo, haciendo énfasis en algunas otras experiencias políticas y sociales. 
Camus desde sus inicios literarios sintió un gran aprecio por su pueblo, Argel, y a la vez amaba a Francia. Su ingreso al partido comunista lo hizo por la necesidad de un cambio de condiciones sociales para Argel, pero éste no se daba por ninguna parte.

Camus siempre fue claro en sus disposiciones y algo que nunca abandonó fue su incondicional lucha por la libertad y la justicia. No podía aceptar que la misma izquierda se tambaleará ante hechos tan claros como las muertes sin justificación y mucho menos el terrorismo de Estado. Sus obras son el fiel reflejo de esta clara posición, como es el caso de su obra de teatro titulada Los Justos.

León Pacheco, en su ensayo sobre El mito de Sísifo, nos dice que :

Nos percatamos que Albert Camus odió toda ideología farsa de la historia, porque amó los hechos concretos más acá de las abstracciones y de los mitos (1968:157).

En este sentido Camus fue inclaudicable. Nada puede justificar la muerte ni el dolor humano; las ideologías se equivocan al fulminar leyes e implantar estados de sitio, no se puede ser neutral ante el terrorismo. El hombre como existente tiene derecho a la vida, a ser libre y responsable, con un compromiso vital de existir hasta las últimas consecuencias.

Camus tuvo que trabajar arduamente en diferentes oficios con el fin de continuar sus estudios de Filosofía en la Universidad; trabajó como vendedor, obrero de fábrica y oficinista. Su situación económica era muy difícil y había que buscar el mejor medio para realizar su cometido, que era obtener un título oficial que lo amparara.

\section{La elección \\ existencial}

Sus primeros escritos datan de 1935, en ese mismo año funda el teatro del trabajador. Al año siguiente escribe su primera obra de teatro titulada: Revolución en Asturias. Luego el periodismo se constituirá en uno de los principales motivos de su vida.

Debido a su salud no puede ejercer el trabajo de profesor de Filosofía, lo que le impidió impartir lecciones en la universidad. Sin embargo no se frustra y sigue adelante hasta convertirse en uno de los intelectuales más comentados en Europa. Cabe destacar también que por su labor artística se convierte en uno de los principales críticos de la época, y también de- 
bido a su posición libertaria, equidad en el trato humano, y uniéndose a las luchas políticas de Argelia por una mayor justicia en la condición social de sus habitantes. Atacó con vehemencia los campos de concentración y el racismo.

Camus ingresa en la resistencia motivado por la ejecución de Gabriel Péri por los alemanes. Es destacable el hecho de que desde muy joven sentía gran abominación por las ejecuciones y las critica en toda su obra. En 1943 se había integrado a un movimiento clandestino llamado "combat". A partir de ese momento su obra literaria y filosófica es más fecunda, aparecen muchas de sus principales obras tales como La peste, El hombre rebelde, La caída, etc.

$\mathrm{Al}$ aparecer el ensayo El hombre rebelde trae consigo el rompimiento con Sartre, del cual había sido amigo íntimo. Se han dado muchas explicaciones acerca de este acontecimiento, pero no está muy claro el asunto; sin embargo la mayoría de críticos concuerdan con que el rompimiento o desacuerdo entre estos dos grandes filósofos, fue de carácter moral e ideológico pues Camus no justificaba la violencia en la revolución.

Ya al final de su vida, estando aún joven, se nota una renovación en sus obras, en que la esperanza brilla como una alternativa ante la convulsión en que se mueve el mundo; esperanza que se trunca al fallecer en un accidente automovilístico, el cuatro de enero de 1960, tres años después de obtener el premio Nobel de literatura.

Con su muerte se cerró un capítulo de la literatura y filosofía francesa, pues perdía en Camus no solo un gran esteta, sino un pensador que con brillo propio cuestionó muchas de las formas de convivencia humana que estaban llevando a la destrucción del hombre, esto trajo como consecuencia que este filósofo tomara decisiones claras y profundas, pues la vida no podía seguir siendo avasallada por ideologías nefastas, y el crimen basado en principios totalitarios o justificado por las ansias de poder.

\section{Tiempos modernos}

Era el reto de los nuevos tiempos, se trataba de curar al hombre de los males que le acosan, como lo proclama Rieux en La peste.

Después de haber hecho un recorrido por la vida de Albert Camus podemos decir que su vida no le fue fácil y que eso lo motivó para que en algún momento desarrolla- 
ra situaciones absurdas en algunas de sus obras, lo que le valió que se le considerara existencialista, pero él siempre fue enfático en rechazar esta calificación. Lo cierto es que existen rasgos que lo caracterizan dentro de la corriente existencialista, haciendo énfasis en su amistad con Sartre y Simone de Beauvoir, pues marcan en parte su temática en sus obras.

Existe un detalle digno de analizar y es que se ha visto el existencialismo como una moda, como lo dirá Sartre en su libro El existencialismo es un humanismo. Creemos que el mismo Camus tenía un mal concepto de esta corriente; lo que sucedió fue que ésta alcanzó una gran popularidad y la llevó a una cierta vulgarización de algunos términos existencialistas y modos de pensar.

Camus, a pesar de ser un hombre moderado en su pensamiento era un hombre exaltado, apasionado en algunos de los campos artísticos como en el caso del teatro que se debate entre el abuso del racionalismo y la irracionalidad, que parece, a veces, tener la existencia.

Yo grito que no creo en nada y que todo es absurdo, pero no puedo dudar de mi grito y tengo que creer por lo menos en mi protesta. (1981:15)
He aquí una de sus más claras representaciones de su pensamiento que lo retomaremos más adelante. El individuo tiene que darse su lugar, no se puede negar todo, pues el nihilismo es también un modo de suicidio.

Pareciera que la misma situación que Camus vive en Argelia le marca un poco el futuro, lo que hace que algunas manifestaciones parezcan desesperadas. Pero hay en sus intenciones algo básico que consiste en mantener lucidez, cuando la desesperación y la angustia parecen derramarse y contagiarlo todo. En su novela La peste por ejemplo al principio la gente corre sin saber hacia dónde va, es la desesperación ante la posibilidad de morir; pero en contraste a ello, existe la acción de hombres como Rieux y Tarrou que buscan la salida al problema y que luchan por una solución a la tragedia. Son ellos conocedores de su destino, los únicos responsables de su existencia y saben que no basta con tener esperanza, hay que actuar:

Sí, tengo un corazón, me sirve para aguantar veinte horas por día, durante las que se ve morir hombres hechos para vivir. Nos sirve para recomenzar cada jornada. Por lo demás, un corazón no bas- 
ta para eso. Los hombres no pueden prescindir de los hombres. (1973:323)

Había en el ambiente histórico que rodeaba a Camus, un aire cargado de angustia y desesperación como consecuencia de una guerra que estaba carcomiendo al mundo; se salía a la calle entre bombardeos y asesinatos, la muerte parecía ser ama y señora, la vida se sacrificaba bajo cualquier pretexto. Esto hace que muchos hombres se aíslen y se desilusionen de un universo que parece no tener remedio.

Albert Camus plantea soluciones, no se trata de evadir, hay que hacer un frente común donde se reivindique al ser humano. Es claro para Camus que no existe un Dios que recompense y que tampoco existe trascendencia que justitique los valores por los cuales los hombres luchan.

De ahí que la posición de Rieux es la posición de Camus; hay un humanismo existencial en ambos, el cual consiste en darle al hombre la oportunidad de vivir dignamente. Se trata de realizarse para llevar a cabo el proyecto de la vida y de

servir al prójimo sin otra satisfacción más que la solidaridad.
En Carnets, Camus nos dice lo siguiente:

Llegado el absurdo y cuando se trata de vivir consecuentemente, un hombre comprueba siempre que la conciencia es la cosa más difícil de mantener del mundo. Las circunstancias casi siempre se oponen a ello. Se trata de vivir la lucidez en un mundo donde la dispersión es regla". (1980:17)

Todos hemos tenido que llegar a esta conclusión en algún momento de la vida. Es nuestro ser, es nuestra existencia lo que entra en juego. Si se opta por la vida se hace la clara elección por existir. Siempre nos elegimos, nos dice Sartre, cualquier toma de decisión es ya una elección. Las circunstancias nos determinan en cierta manera y aunque la realidad a veces se nos presenta dispersa se hace necesario ordenar ciertos elementos de ella y actuar; no se trata de escapar de esa realidad sino de enfrentarla con todas sus consecuencias. La humanidad pasaba por un momento difícil, dos guerras mundiales ensombrecían el ambiente. Sólo una mente muy lúcida podría adaptarse en parte a ese mundo y Camus lo asume como un reto de la existencia; hay una honradez desesperada en él. Cualquier hombre puede sentir esa angustia de verse atrapado por el absurdo. Pe- 
ro ante un hecho concreto, ante el sufrimiento de un niño no se pueden buscar justificaciones ni optar por decir: "No es conmigo el asunto".

El papel principal de la elección existencial consiste en permitir al hombre el pasaje a la existencia, donde se concrete el proyecto de existir a cabalidad. El absurdo puede surgir en cualquier momento, pero esto es solo una parte de un todo que es la vida humana: hay días tristes y días de alegría. Quizá la felicidad en sí no exista, pero hay instantes en que se puede disfrutar.

En la obra de Camus, a veces aparecen personajes que se divierten $\mathrm{y}$ en algunas ocasiones parecen ser irónicos, pero en realidad son una manera de aliviar el cansancio diario.

Camus no encontró justificación a las injusticias cometidas por los regímenes totalitarios en su época, habrá que buscar soluciones y una de ellas era el compromiso social y político de cada individuo ante los gobiernos de opresión. En cuanto a la literatura se refiere, no era hacer simplemente un cierto tipo de literatura o una literatura al servicio de una determinada ideología, se trataba, más bien, de hacer una literatura social, en donde el com- promiso interno del individuo con la sociedad es lo fundamental; tengo que saberme dueño de mis actos y por lo tanto asumir las consecuencias que de ellos se deriven. Si yo soy libre, soy el garante de esa libertad.

Ignacio Lepp en su libro La existencia auténtica nos dice que :

Mientras el hombre no contraiga un compromiso que ligue irrevocablemente todo su ser con todas sus situaciones pasadas presentes y futuras, permanecerá inevitablemente en la condición infraexistencial, en estado de depresión y pasividad". (1977:126)

En el caso de Camus las palabras de Lepp se hacen ciertas. Su lucha política, su discurso moral, sus esfuerzos en favor de la humanidad lo hacen un hombre íntegro. Camus no solo compromete su palabra sino su propio ser. Conciente de que está inmerso dentro de una sociedad, no como un objeto de ésta sino como un sujeto.

En toda la obra de Camus se revela la preocupación por la realización personal. Tarrou en La peste se pregunta ¿Cómo se puede ser santo aún sin creer en Dios? Rieux lucha por sanar esa humanidad contaminada por la peste. Todos los problemas modernos están 
aquí presentes, entre el silencio del mundo y el grito desesperado de los oprimidos.

Nos falta definir un poco más la relación entra Camus y el existencialismo.

\section{Camus}

\section{$y$ el existencialismo}

Albert Camus nunca quiso aceptar que los críticos lo ubicasen dentro del existencialismo, más bien tenía un mal concepto acerca de esta corriente filosófica. Sin embargo el existencialismo no es una corriente homogénea, existe un gran trecho entre un pensador y otro, los hay más moderados como Karl Jaspers y más extremos como Jean Paul Sartre.

Lo que sucedía era que a mediados del siglo XX, a todo aquel que utilizara cierto lenguaje o manejara algunas ideas existenciales se le consideraba existencialista. El mismo hecho de poseer un tipo de ateísmo permitió que se identificará a muchas personas con esa corriente filosófica, aunque en el fondo nada había en común.

Por ejemplo Charles Moeller nos dice lo siguiente :
Ignoro cómo se ha podido embarcar a Camus en la galera del existencialismo. El barullo de los primeros años de la postguerra influyó indudablemente en ello. Por entonces, basta escribir las palabras absurdo, sin sentido para ser encuadrado en la tropa heteróclita mandada por el patriarca del Café de Flore “.(1955:35)

Podemos decir que Camus realmente no fue existencialista, el hecho de que empleará conceptos afines al existencialismo, no significa que se adhiera a esta corriente filosófica.

Bien sabemos en nuestros días que el devenir humano es dialéctico. Nuestra vida es una eterna contradicción, existimos entre luchas y peripecias. Es ahí donde el ser tiene que enfrentarse a cada instante a circunstancias distintas que ponen obstáculos a la realización personal.

Ignacio Lepp cuando hace referencia al ser nos comenta que el hombre no puede desatenderse de las luchas, combates, sufrimientos y aspiraciones de la humanidad, aunque el camino o el proyecto de la vida de cada individuo se le presente lleno de incertidumbre.

Por tal motivo tiene razón Sartre al decir que elegimos siempre, y que 
somos los únicos responsables de nuestra existencia. Ante el hecho de enfrentarnos a nuestra propia imagen no podemos cruzarnos de brazos, tenemos que optar por una decisión responsable.

Camus se encuentra inmerso dentro del panorama anteriormente descrito. No trata simplemente de analizar el absurdo y el sin sentido de la Vida, sino más bien de superarlos:

La conclusión última del razonamiento absurdo es, en efecto, el rechazo del suicidio y el mantenimiento de esa confrontación desesperada entre la interrogación humana y el silencio del mundo". (1981:12)

La angustia existencial se presenta por la situación difícil de la vida y ella se alimenta de la irracionalidad en que se desenvuelve la sociedad. Cuando el sufrimiento de los niños y de los inocentes no tiene ninguna justificación lógica, estamos ante el absurdo.

El hombre es la única criatura que se niega a ser lo que es, reflexiona Camus en El hombre rebelde. El sentirnos arrojados en un mundo donde parecemos ser extranjeros, trae consigo ese desarraigo que nos quebranta la fe y a veces la esperanza. Pero el rebelde de Ca- mus desafía, más que niega, no se deja atrapar por el nihilismo ni tampoco acepta las condiciones que lo envuelven ante determinado hecho. El rebelde no opta por el suicidio sino por la revuelta que conduzca al cambio de condiciones de vida, tratando de no apartarse de los principios de la rebelión.

Lo que ha sucedido a la Europa de mediados de siglo y lo que sucede hoy, es que la vida se ha convertido en una costumbre más, muy lejos de disfrutarla intensamente en todo lo que tiene de su esplendor.

En alguna oportunidad leíamos un cuento popular que se refería a la historia de un músico que por andar de serenata en serenata, de fiesta en fiesta, se cansó y destruyó su guitarra, maldiciendo el momento en que aprendió a tocar ese instrumento. El nihilismo cobra fuerza cuando el espíritu se abate y todo comienza a oscurecerse. Meursault, en El extranjero ha perdido todo, pareciera insensible, casarse o no casarse, morir o no morir, ocupa el mismo lugar en su existencia. De ahí que se haya querido ver a este personaje como algún reflejo fiel de Camus, lo cual como hemos venido apuntando no guarda ninguna o muy poca relación.

Un aspecto destacable en Camus es que sus obras de ficción son 
bastantes diferentes a sus ensayos, y eso es lógico; podríamos decir que su verdadero pensamiento es el que se refleja en sus ensayos y artículos de periódico y que sus ficciones reflejan parte de esa sociedad en que habita y ante la cual se rebela, tratando de encontrarle un valor a la existencia.

León Pacheco, a pesar de tener el criterio de que Camus es existencialista nos dice lo siguiente, lo cual aprueba en cierto modo lo que pensamos:

El escritor, después de haber publicado El extranjero, entró a la resistencia,y fue en los contactos humanos, en esa aventura llena de riesgos, que encontró que el hombre es digno de un destino humano, precisamente porque vive entre los demás hombres." (1968:199)

Es muy posible que León Pacheco tenga razón, en que hubo un momento en que Camus se debatió en una crisis existencial, que lo puso al borde del precipicio de la indiferencia, pero un corazón sensible como el de Camus no podía cerrarse ante una realidad evidente que le mostraba que hacían falta hombres que levantaran su voz, su protesta, ante la injusticia y la muerte de inocentes. Su angustia se debió sobre todo a la claridad de conciencia que poseía.

Para una persona insensible ni siquiera el absurdo presenta problema:

Todo hombre que se contente con la inautenticidad de su existencia, hace traición a la humanidad, rehusa asumir la trascendencia absoluta de su yo sobre la naturaleza, se cosifica. (Lepp, 1977:26)

Esta opinión de Ignacio Lepp nos parece adecuada de acuerdo con lo que estamos tratando porque el pensamiento existencial no significa negación sino acción, y porque al estar el ser en un constante hacerse le da sentido al proyecto de su vida. Es por eso que el ser humano en su constante hacerse, realiza su mayor proyecto, existir.

\section{Un espíritu paciente y racional}

Continuando con nuestro objetivo, hacemos referencia a Guillermo de Torre, historiador de la literatura que nos dice lo siguiente:

Indudablemente Camus no fue existencialista. Sin embargo, como quiera que sea, ciertos temas manejados por Camus, o más 
bien a su manera de encararlos, no dejan de mostrar semejanzas con otros de los existencialistas. (1973:74)

Camus era de un espíritu prudente, eso lo sabemos, capaz siempre de no dejarse dominar por las abstracciones inhumanas, de no cegarse ante las ideologías y afirmar la supremacía de la dignidad de la persona por encima de toda otra cosa. Por eso dice Guillermo de Torre que Camus salta del nihilismo a la esperanza.

Los hombres mueren y no son felices había dicho Calígula una vez. El hombre busca la felicidad en todas partes, pero ésta se le niega. La angustia que ocasiona el anhelo insaciado de bienestar hace que muchos hombres le nieguen valor a la existencia, o por el contrario sacrifiquen toda una vida en aras de un paraíso donde sí existe la verdadera felicidad. Esta idea no es nueva, la han vivido millones de hombres.

Camus no está de acuerdo con que se sacrifique esta vida por un paraíso del cual nada puede afirmarse. El doctor Rieux, Tarrou, Meursault, Clamence y muchos otros personajes lo reflejan en su visión de la vida, en su ideario. Son hijos de esta tierra como el mismo Camus, que no aspiran a trascender, pero que sí anhelan una santidad sin Dios, donde el fin es el hombre por el hombre.

Aún así Jonás el pintor es feliz, el doctor Rieux se siente realizado y la mujer adúltera se siente bien con la naturaleza, aquí existe un aire de felicidad que contradice el absurdo.

Guillermo de Torre refiriéndose a Camus nos comenta lo siguiente:

En suma, al situarse más allá del nihilismo, da paso a la esperanza, avista los dominios de la lucidez para desembocar, finalmente en el último capítulo del Hombre rebelde, donde su espíritu mediterráneo clásico, afirma el sentido de la medida y creación, frente a la desmesura y destrucción. (1974:87)

Cuando se lee El hombre rebelde y se compara con obras anteriores, se nota la clara evolución de Camus, pues en esta obra afirma su deseo de alejarse de posiciones complicadas, y de tomar posición radical por los desposeídos, pero no al estilo socialista o capitalista, sino guardando la medida. Donde no se le da paso a la violencia, la cual nunca podrá tener defensores. 
La violencia ha sido ama y señora de la humanidad. Todas las revoluciones han terminado asesinando; por eso el pensamiento del mediodía debe ser aquel en que se respete al ser humano y por ende la vida. Es aquí donde más se aleja Camus del existencialismo para optar por una moral, contrario a Sartre que pensaba que ésto no era posible.

El padre Paneloux, en La peste, vislumbrado por los nuevos modos de pensar, casi, en un gesto herético, expresa:

Hermanos, ha llegado el momento de aceptar todo o negarlo todo. (1987:145)

Paneloux dice esto al ver avanzar la peste y al observar la muerte de muchos inocentes. Negarlo todo significa reconocer que la fe no era suficiente. Hay representada una impotencia religiosa, pero está su contraparte, la del doctor Rieux.

Nuevamente aquí Camus se vuelve hacia los hombres como fin. Charles Moeller en su ensayo sobre Camus, titulado La honradez desesperada nos dice lo siguiente:

No es en su dimensión trágica como se manifiesta en Camus el tema de la condición humana, condición y no naturaleza. El polo de su universo es la búsqueda de la dicha; esa especie de felicidad o alegría que enriquece sus obras, Camus debe ser situado en la literatura de la dicha, no en el de la salvación. (1955:47)

Si el papel principal de la elección existencial tiene como objetivo permitir al hombre integrar su ser, a partir de sus propios actos en un accionar consciente y responsable, permitir al hombre aliviar la carga que presenta la existencia. El existente en vez de negarlo todo, llena su espíritu con esas situaciones donde la naturaleza es un aliciente y la ternura desemboca en gestos que dignifican a la persona. Camus es el filósofo de la dicha, no de la salvación.

Meursault, en El extranjero, a pesar de sufrir la muerte de su madre disfruta del mar. No es que no sienta la muerte de su madre, sino que sabe que nada remedia con llorar o desesperarse.

Si la condición del ser es la de estar en un mundo que a veces nos doblega, el objetivo del hombre entonces será buscar esos instantes que lo recompensan. Camus amaba la naturaleza y todos los personajes de sus obras disfrutan de ella. Pero la dicha no es solo 
una satisfacción física, sino un estado anímico donde el hombre se siente realizado.

Clamence, en La caída después de hacer un acto de contrición siente una dicha, y esa se refiere al hecho de haber adquirido conciencia de lo que ha sido su vida.

Camus sabía que el hombre no podía hacerlo todo, que muchas cosas ni siquiera están en sus manos, pero que esto no era motivo para no luchar.

León Pacheco, refiriéndose al ensayo El hombre rebelde y comentando la forma de discurso que utiliza Camus en dicho libro nos dice que:

Si Camus, por lo menos en este alegato abandona el círculo vicioso de sus concepciones-existenciales razón y no razón, absurdo y esperanza, nada y ser, es para hacerle frente al problema humano de porqué en menos de cincuenta años se han asesinado más de setenta millones de seres para justificar ideologías crueles, aduciendo siempre el principio de que el hombre es libre. (1966:179).

Aunque León Pacheco razona bien, lo que hay que aclarar es que Camus no simplemente abandona el lenguaje existencial, sino que hay toda una nueva disposición.
Camus ha adquirido conciencia de la situación del hombre en el mundo y como tal la enfrenta. Como gran escrutador del alma humana, trata no sólo de analizar el problema social sino individual y también profundiza el porqué de muchas actitudes.

\section{CONCLUSIONES}

La obra de Camus fue siempre un semillero de sugerencias, y una voz de alerta ante los abusos de los gobiernos totalitarios, obra que quedó inconclusa con su muerte, pero que aún hoy nos sigue induciendo al diálogo entre los hombres.

Camus debe gran parte de su obra básicamente a tres pensadores. Andre Gide, de quién hereda sus inquietudes estéticas, Nietzsche de quien recoge el vitalismo, la defensa del hombre como hombre, y luego de Dostoievsky, el arma con que succiona el alma humana y lo hace capaz de crear escenas conflictivas, donde el ser humano con todas sus fuerzas y debilidades es el principal actor, y las pasiones humanas se desbordan y los sentimientos florecen amparados por la rebelión.

Camus no era muy original en sus temas, muchos los tomó del mis- 
mo Dostoievsky, pero les da un toque personal inigualable. No en vano recibió el premio Nobel de literatura en 1957.

Analizado por nosotros y auxiliados por otros pensadores podemos derivar algunas conclusiones. Una de ellas es que Camus definitivamente no fue existencialista al estilo de un Sartre o un Heidegger, pero que sí utilizó lenguaje existencial en muchas de sus obras con originalidad.

Otra conclusión y que no es solo nuestra, es que no se puede generalizar que el existencialismo es un movimiento negativo, ni tampoco se puede juzgar a Camus sólo por algunas obras como es el caso de El extranjero o Calígula, ya que su pensamiento es una clara evolución que lo hace cambiar de temática y presentarse como un defensor de los derechos humanos y de la justicia.

En conclusión diremos que Camus vivió con una honda convicción:

Nada hay más allá de esta vida y que no se puede sacrificar la libertad humana por un Dios que nos limite. (1955:43)

Hay un rechazo claro de las religiones, que para Camus son alienadoras del ser.
En lo político tenemos que decir también que Camus no fue un hombre de ideologías absolutas. Dejó el socialismo y aborreció siempre la sociedad burguesa capitalista, ya que no aceptaba sus injusticias. Aborrece las dictaduras y el crimen, hace de su vida una lucha sin fin contra el despotismo. A fin de cuentas importa más su mensaje de justicia que el hecho de si fue o no existencialista.

A manera de conclusión general y como apuntábamos en la introducción a este artículo, la importancia y la vigencia del pensamiento de Camus se refleja tanto en su concepción moral y política de este mundo como también en el propósito principal de su visión de la vida y que es el diálogo como fuente primordial para salvar vidas a costa de las guerras y las enfermedades. La problemática sobre qué mundo iremos a formar en el futuro, es un tema central y de suma importancia. Por ello la importancia del estudio de las ideas existenciales de Albert Camus estriba en la escogencia que el hombre determine en su propia existencia para su proyecto de vida, y en cuanto a los pueblos serán dos alternativas: la primera será una alternativa de sujeción y explotación o la otra como la formulación de un proyecto político común. Por supuesto Camus abogará por 
la posibilidad de crear nuevos espacios de identificación y de participación en todos los niveles de la vida social y por lo pronto ese será el legado que nos dejará el autor de El extranjero.

\section{BIBLIOGRAFÍA}

Camus, Albert. (1979) El extranjero. Traducción de Bonifacio Del Carril. Novena edición. Buenos Aires: Emecé Editores.

Camus, Albert. (1981) El hombre rebelde. Traducción de Luis Echáverri. Décima edición. Buenos Aires: Editorial Losada, S.A.

Camus, Albert. (1987) La peste. Traducción de Rosa Chacel. Cuarta edición. México. D.F.: Ediciones Hermes, S. A.

Camus, Albert. (1973), Obras Completas Traducción de Carlos Saínz de Robles. Tercera edición. México D.F.: Editorial Aguilar, S.A.

Camus, Albert. (1980). El mito de Sísifo. Traducción de Luis Echáverri. Décima edición. Buenos Aires: Editorial Losada, S.A.

Camus, Albert. (1980) Carnets. Traducción de Luis Echáverri. Décima edición. Buenos Aires: Editorial Losada, S. A.
Copleston, Federico. (1976) El existencialismo. Traducción de Eduardo Valenti. Segunda edición. México: Editorial Tradición, S.A.

De Torre, Guillermo. (1974) Literatura de Vanguardia. Edición Tercera. Madrid: Editorial Guadarrama.

Ellison, David. (1990) Entendiendo a Camus. Edición primera. Editorial Columbia, Universidad del Sur de Carolina.

Lepp, Ignace. (1977) La existencia auténtica. Traducción de Alicia B. Gómez. Buenos Aires: Editorial Carlos Lohlé, S.A.

Mccarthy, Patrick. (1991). The Plague in Albert Camus. Editorial Harrold Bloom, New York.

Moeller, Charles. (1955). Literatura del siglo XX y Cristianismo. Madrid: Editorial Gredos, S.A.

Pacheco, León. (1968). Tres ensayos apasionados. Segunda edición. San José, Costa Rica: Editorial Costa Rica.

Rigobello, Armando. (1961). Camus. Traducción de Albert Vaccaro. Tercera edición. Buenos Aires: Editorial Columba, S.A.

Tarrou, Susan. (1985). El exilio y el Reino: Un estudio político de Albert Camus. Alabama University.

Todd, Oliver. (1998). Albert Camus: A Life Benjamin Ivry. Carroll and Graff. Georgia Atlanta. 